Revista Iberoamericana, Vol. LXXIV, Núm. 223, Abril-Junio 2008, 455-470

EL CINE URBANO Y LA TERCERA VIOLENCIA COLOMBIANA

POR

\author{
GEOFFREY KANTARIS \\ University of Cambridge
}

\begin{abstract}
Cuando uno habla con personas que han vivido o viven las mil guerras que se dan en este país, siempre se encuentra con que la fatalidad y el absurdo son las únicas maneras de representarse la experiencia de la violencia. La violencia parece venida de otra parte, transferida al ahora y al aquí. Es un monstruo informe regido por algo anterior a la razón; está marcada por una incomprensibilidad que la define.
\end{abstract}

Víctor Gaviria ${ }^{1}$

La representación de la violencia en Colombia es siempre un acto de desplazamiento aun cuando se determina dentro de un campo de des-plazamientos violentos. Es un desplazamiento histórico, porque el proceso histórico conocido con el nombre de la Violencia, que se reduplica en cada década y se vuelve cada vez más amplio, consume toda representación de la violencia desde 1948 por lo menos. Es un des-plazamiento geográfico, porque la Violencia es lo que destruye el espacio, literalmente, al desplazarse desde las redes urbanas hasta los lugares más recónditos del campo, para luego producir un movimiento inverso de migraciones masivas de poblaciones desde el campo hasta las periferias, $\mathrm{y}$ a veces hasta los centros abandonados, de las crecientes ciudades. Y es un desplazamiento figurativo porque la violencia no se puede representar, sólo transformarse en fatalidad, en objeto fetiche, o a su vez desplazarse hacia otros campos de la representación.

No es de sorprenderse, entonces, que los “violentólogos", al intentar clasificar la Violencia por períodos, muchas veces se vean obligados a representarla en términos de la multiplicación y la diseminación: "la primera Violencia”, “la segunda Violencia”, “la tercera Violencia”. ${ }^{2}$ En tal esquema, la Violencia original es la que se da en torno a los sucesos de 1948, el llamado Bogotazo, que se explica en otras páginas de este número. La segunda Violencia es la violencia rural asociada con el auge de las facciones guerrilleras y la respuesta paramilitar, que se desata a partir de los sesenta y que es responsable en gran medida de las migraciones masivas de la población rural hacia los llamados "barrios

\footnotetext{
${ }^{1}$ Entrevista a Víctor Gaviria por Carlos Jáuregui (98).

${ }^{2}$ Para una explicación de la correspondencia entre estas etapas históricas y el arte y cine colombianos, véase Medina, “El arte y la violencia” (19), y Pulecio, “Cine y violencia” (161-80).
} 
de invasión” -nombre fantasmal de miedos indefinidos- en las tres capitales regionales, Bogotá, Medellín y Cali, y también en muchas ciudades más pequeñas. La tercera Violencia denomina la violencia urbana ocasionada por el desempleo y pobreza de estas poblaciones marginales en las grandes ciudades, vinculada al auge, desde mitades de los ochenta, de las mafias de la droga en Medellín y Cali que se aprovechan brutalmente de esta mano de obra barata. No es difícil plantear un cuarto horizonte posible de la Violencia colombiana, uno que nombraría la globalización de la violencia, resultado del desplazamiento de las operaciones de tráfico, soborno y lavado de dinero hacia países como México, Italia, Rusia y, desde luego, los Estados Unidos, junto con una migración masiva que desborda las fronteras nacionales.

A pesar de que tales clasificaciones de la Violencia, según períodos, pueden resultar útiles, la desesperada reduplicación y diseminación de la Violencia-que es también un movimiento desde lo específico (el Bogotazo) hacia lo difuso (el crimen urbano y la corrupción globalizada) - es una muestra de cómo la violencia, en tanto proceso de des-anclaje y de des-espacialización, siempre excede sus marcos espaciales, temporales y conceptuales. Y también de la creciente dificultad para enfocar sus efectos y consecuencias dentro de los discursos históricos, sociológicos y culturales. ${ }^{3}$ Cualquiera que sea el sistema clasificatorio de la Violencia, no debe permitirse una visión de ella como una enfermedad orgánica que surge al azar y va contagiando todo el cuerpo social. La violencia no es nunca una causa en sí misma, sino un síntoma, y como veremos, reconocer esto es darse cuenta de la naturaleza sistémica de la violencia, del hecho de que la violencia es tanto un efecto de la representación como un sistema de representación de por sí. Esta infusión de la violencia con los mismos sistemas de representación que ella va articulando y desarticulando, es algo que, según el teórico de la comunicación Jesús Martín-Barbero, la violentología no ha podido explicar:

a la vez que [los violentólogos] nos han ayudado a entender la multiplicidad de violencias que encadenan este país, no han hecho nada para comprender la envergadura antropológica, es decir, el espesor cultural de esas violencias, tanto de su origen como de su trama. (Al sur... 235)

En este artículo me centraré en las obras cinematográficas que enfocan esta tercera fase urbana de la violencia colombiana. Se examinarán tres largometrajes de los años ochenta hasta hoy para poder analizar algunas de las estrategias que adoptan para representar los efectos de la violencia -las heterotopías y heterocronías que parece generar- pero también, y muchas veces de forma más radical, la imbricación de la violencia con sistemas de representación. Las películas principales de este análisis serán: Pura sangre, de Luis Ospina; La virgen de los sicarios, película basada en la novela homónima de Fernando Vallejo, y dirigida por Barbet Schröder; y Sumas y restas, la última película de la trilogía sobre Medellín, dirigida por Víctor Gaviria.

${ }^{3}$ Una película colombiana de los años ochenta, Pisingaña, parece señalar una idea parecida al caricaturizar la división de la Violencia en etapas simplistas por parte de los miembros de la burguesía, que no logran entender la imbricación de su propio estilo de vida con las causas y consecuencias de la violencia social. 
VIOLENCIA URBANA, FETICHISMO Y VISIBILIDAD

Lallamada “tercera violencia” en Colombia tiene sus raíces en los grandes desplazamientos de las poblaciones rurales ocasionados por la Violencia y su posterior transformación en lucha guerrillera y paramilitar. Como tal, responde a un marco histórico nacional dentro del cual la violencia ha sido un sistema de representación cuyo fin es conceder o negar la visibilidad y/o la significación a grupos enteros de la población civil (y hasta suprimirlos del todo). Sin embargo, no cabe duda de que la ola de violencia urbana a partir de los ochenta se inserta también dentro del marco de las transformaciones estructurales del capitalismo global que tienen como producto un "cuarto mundo", y que se percibe como tal en varias de las películas que relatan esta violencia. Así lo explica Manuel Castells en el último volumen de su trilogía sobre la Edad de la información:

Hay una relación sistémica entre las transformaciones estructurales [...] de la "sociedad de las redes” y el creciente abandono en el que cae el gueto; la constitución de una economía informacional/global, bajo las condiciones de la re-estructuración capitalista; la crisis del estado-nación [...]; la desaparición de la familia patriarcal [...]; el auge de una economía criminal, global pero descentralizada [...]; y el proceso de enajenación política, y defensa comunal, entre los grandes segmentos de la población que son pobres y se sienten privados de representación. [...] El cuarto mundo [...] está poblado de millones de gente sin hogar, encarcelada, prostituida, criminalizada, brutalizada, estigmatizada, enferma y analfabeta [...] a medida que los criterios selectivos del capitalismo informacional y el colapso político del estado de bienestar intensifican la exclusión social. En el actual contexto histórico, el crecimiento del cuarto mundo es inseparable del crecimiento del capitalismo informacional a nivel global. (End of Millennium 138, 164-65 [traducción mía])

No hay que olvidar que la violencia urbana de los ochenta y noventa en Colombia, y en especial la vinculada al sicariato, ${ }^{4}$ es producto de una mezcla de la fuerte exclusión social experimentada por los jóvenes de los guetos urbanos y el crecimiento de una poderosa industria criminal globalizada que operaba-y opera-dentro de los más estrictos paradigmas del "capitalismo informacional” citado por Castells: producto efímero y ligero de alto valor, compulsión de consumo, producción transnacional, desconocimiento de las fronteras nacionales, evasión de impuestos, soborno y clientelismo, y ocultamiento de las ganancias tras un montón de importaciones a precios de ficción. Éste es un tema que varias películas del período enfatizan, desde la representación del capitalismo vampiresco en Pura sangre hasta la semejanza entre los objetos de consumo desechables y los sicarios "desechables" de La virgen de los sicarios y los flujos de sustancias y dinero que descolocan y disuelven las estructuras sociales más elementales en Sumas y restas.

La violencia que se representa en estas películas dista bastante de la que se registra en la cultura masiva del mercado global, aunque a veces hace uso de su lenguaje. En ésta, la violencia de los márgenes de la sociedad es casi siempre o monstruosa o erotizada y convertida en fetiche. Aun en un género más sutil como el ya clásico del film noir, del cual

\footnotetext{
${ }^{4}$ Nombre que se da en Colombia al fenómeno y período de operación de los sicarios, o sea jóvenes
} que se contratan como asesinos. 
hay un ejemplo colombiano algo desplazado en Soplo de vid $a,{ }^{5}$ el inframundo criminal está supeditado al desorden libidinal provocado por la femme fatale, y la posible resolución de este desorden se relaciona firmemente con el restablecimiento del orden social patriarcal. Sugiero que la violencia que se registra en el cine urbano colombiano es de orden más sintomático. Según esta lectura, lo sintomático sería la antítesis de lo fetichista, puesto que los modos de representación fetichistas dependen muy precisamente de un proceso más o menos perfecto de ocultación o denegación del síntoma. Una lectura sintomática de la violencia -y estas películas son una lectura en este sentido- de igual modo que una lectura alegórica, insiste en el desplazamiento y la dislocación, la violencia no como una pantalla (de la identidad del macho fuerte, por ejemplo) sino como un corte en la pantalla, la forma presente de otra escena. ${ }^{6}$ Las películas que me interesan aquí niegan cualquier fetichismo de la violencia -o exponen los mecanismos de su funcionamiento-, se oponen a la asociación casi pavloviana entre violencia y espectáculo con que está programada la cultura masiva estadounidense, al tiempo que revelan muchas veces la complicidad entre "medios y miedos" que ella vehicula (Martín-Barbero, Al sur... 134). Registran, en cambio, los actos de violencia urbana como los temblores de catastróficos desplazamientos nacionales y geopolíticos.

Si estas películas intentan acercarse a otra escena -a una escena invisible-, es lógico que sólo pueden hacerlo a través de un cuestionamiento de su propio modo de representación (en tanto ejemplos de cultura visual). Sin embargo, la reflexividad en estas películas no se da con miras a la película en sí (auto-reflexividad), sino con miras a la visibilidad o invisibilidad de sus sujetos, involucrando el acto mismo de ver y los modos de ser visto o no visto en una sociedad tan mediatizada por la imagen y el espectáculo como cualquier otra. Todas estas películas sugieren las relaciones sistémicas que subyacen a las representaciones de la violencia intersticial, las laceraciones y rajadas en las pantallas de la nación y (en las más recientes) de la globalización. Sugieren que hay vínculos escondidos y específicos entre crimen-violencia-pobreza en un lugar y los flujos de riqueza en otros; por lo tanto remiten a "la cada día más espesa relación entre información y violencia” (Martín-Barbero, Al sur... 64) y exponen "la geometría del poder de la compresión espacio-temporal".7 Sugieren, también, la oposición delineada por Castells entre “el espacio de los lugares” y "el espacio de los flujos", ${ }^{8}$ es decir, el arrasamiento de los lugares de interacción social, de vida comunitaria, que dieron sentido a la memoria y la identidad personales, y su conversión

\footnotetext{
${ }^{5}$ Es el segundo largometraje de ficción de Luis Ospina, ambientado en una Bogotá convertida ingeniosamente en cita fílmica de casi todos los clásicos norteamericanos del noir. Esta película señala su propio fetichismo fílmico (junto con el de sus personajes), y lo usa como metáfora autoconsciente de los múltiples desplazamientos de la violencia que se dan en la cotidianidad urbana.

${ }^{6}$ Estos términos se relacionan con la teoría fílmica psicoanalítica, por ejemplo Metz.

${ }^{7}$ Doreen Massey (149). La compresión espacio-temporal es una expresión usada por David Harvey y otros para señalar la aceleración de las comunicaciones experimentada en forma de la anulación del espacio en los regímenes de la acumulación capitalista desregulada, "flexible” y global.

8 "The Space of Flows" en The Rise of the Network Society (376-428). La oposición conceptual entre espacio y lugar tiene su origen en la obra de De Certeau. Véase también Martín-Barbero, Oficio de cartógrafo (264).
} 
en espacios de tránsito anónimos y desterritorializados, de compra y venta de terrenos y lotes, de fragmentación de la experiencia y de la memoria.

\section{VAMPIRISMO URBANO}

Uno de los más tempranos ejemplos de esta nueva sensibilidad en el cine de ficción en Colombia es Pura sangre del caleño Luis Ospina. Este largometraje, ambientado en Cali, vincula los imaginarios urbanos del miedo (producto del crecimiento y pauperización de la ciudad, de la inmigración masiva y el aumento en los actos de delincuencia común) al auge de una nueva forma de "capitalismo salvaje”, depredador y vampiresco. Uno de los aspectos más interesantes de la película es la forma en que combina en un nudo imaginario varios fenómenos y miedos relacionados con el espacio de los flujos: transfusiones de sangre como metáfora del vaciamiento y consumo de los cuerpos y de la juventud, hibridación de razas, culturas y lenguajes, el capitalismo depredador y “chupasangre”, los miedos provocados en la imaginación popular por la homosexualidad y la pedofilia, y el flujo de narcóticos e ingestión de "sustancias" ilegales.

La película narra la historia de un viejo capitalista enfermo, Roberto Hurtado, que tiene una enfermedad de la sangre cuya única terapia consiste en hacerle transfusiones masivas y frecuentes de sangre fresca, proveniente de jóvenes de la misma raza y sexo. Tres empleados de la familia -un chofer que es fotógrafo (Perfecto), otro chofer exparamilitar (Ever) y la enfermera (Florencia) - se ven obligados por Adolfo, el hijo de don Roberto, a buscar la sangre que éste necesita por medio de secuestros a niños y adolescentes de las calles nocturnas de Cali, sin que Roberto lo sepa. Los raptan de la calle, los drogan, los hombres -ambos homosexuales- gozan a veces con sus cuerpos, la enfermera los desangra totalmente, y luego botan sus cadáveres. Las desapariciones de jóvenes cuyos cuerpos amanecen violados y extrañamente desangrados provoca un creciente miedo entre la población y la invención de un mito urbano sobre el "monstruo de los mangones”, el cual se ve fomentado por los medios de comunicación masiva. Mientras tanto, el hijo de don Roberto, don Adolfo, emprende un tráfico ilegal de azúcar con Venezuela ligado a un intento de fraude a la compañía de seguros, el cual se malogra, provocando un intento de suicidio por su parte. Extrañamente, al final de la película, la policía captura al "responsable" de los secuestros, un trabajador negro segador de caña quien, por televisión, reclama ser el monstruo de los mangones y se declara culpable de los raptos.

La película parece ser una alegoría bastante clara del incipiente desarraigo y desencaje (Ortiz 144) provocado por los procesos urbanos, el modo en que el capitalismo termina por consumir y desmaterializar los cuerpos junto con los lugares que habitan y las relaciones sociales que les dan coherencia. Es una idea que resume Martín-Barbero al hablar del proceso urbano de la des-espacialización:

La materialidad histórica de la ciudad en su conjunto sufre así una fuerte devaluación, su "cuerpo-espacio" pierde peso en función del nuevo valor que adquiere su tiempo, "el régimen general de la velocidad" [Virilio]. No es difícil ver aquí la conexión que enlaza esa descorporización de la ciudad con el cada día más denso flujo de la imágenes devaluando y hasta sustituyendo el intercambio de experiencias entre las gentes. (Al sur... 130) 
En Pura sangre, estos procesos fluyen por tres vertientes principales: la Violencia en tanto protagonista de la dis-locación social; la corporalidad en tanto lugar privilegiado del consumo (hedonista) y escenario de hibridaciones e impurezas; y los medios en tanto mediadores y amplificadores del miedo. Don Roberto parece ser un capitalista benigno y ético, interesado en fomentar relaciones pacíficas entre sus trabajadores y su compañía, y la iglesia lo pinta como un salvador de los pobres. Sin embargo, tanto su riqueza como su vida dependen, literalmente, de la destilación y flujo de productos cuya pureza es altamente cuestionable, ya sea el procesamiento y contrabando del azúcar o la transfusión de la "pura" sangre que lo mantiene vivo.

La Violencia es referida por una charla entre los dos choferes, Perfecto y Ever, acerca de unas operaciones paramilitares en el Norte del Valle en las que tomó parte éste. Relata el asesinato de un campesino, cómo "empezó a pedir cacao" (misericordia) cuando se dio cuenta de que lo iban a matar, diciendo que tenía cinco hijos, y cómo le dieron dos tiros por la espalda, saliendo una bala por el otro lado de su cuerpo con pedazos de corazón y el retrato de su hija que llevaba ahí. Hablan así para pasar el tiempo mientras que Florencia está desangrando el cuerpo de la primera víctima. La transferencia de la violencia rural al escenario urbano, proceso que en Colombia genera y constituye lo urbano, y su posterior transformación en consumo casi literal de cuerpos “desechables”, no podría tener una alegoría más clara.

La ciudad latinoamericana siempre ha pensado su modernidad en términos de defensa contra las impurezas ocasionadas por la mezcla de clases, hibridación de razas, culturas y lenguajes que implican su acelerado crecimiento. Aquí, estas mezclas fantasmales se somatizan con la metáfora de las transfusiones de sangre y su corolario defensivo, o sea la necesidad de mantener ciertas reglas y ceremonias de "pureza” en medio de los flujos y confusiones de cuerpos. Se dice al principio de la película que don Roberto tiene una fobia contra los microbios, y las características de la sangre que necesita son muy exigentes: Florencia deja entender que no se puede usar sangre de gente de diferentes razas ("negros no”). Sin embargo hay profusión de mezclas y acoplamientos no "tradicionales” en la película, sobre todo relacionados con la homosexualidad y la ingestión de sustancias. Una secuencia tiene lugar en un club medio gay donde Ever seduce, en el closet, a un muchacho por medio de cocaína e insinuación de sexo; más tarde, vemos a Perfecto ajustando sus pantalones después de violar el cuerpo drogado de uno de los muchachos. La constante aspiración de cocaína, por otra parte, sugiere que el cuerpo se ha hecho parte de la cadena de consumiciones, convirtiéndose en el escenario mismo de la ideología del consumo.

En esta película se entiende la violencia urbana tanto en su dimensión de producto de un capitalismo racionalizadamente salvaje como en su dimensión mediática y la película ayuda a pensar la relación entre estos procesos tal como los describe Martín-Barbero en la cita ya mencionada. El flujo creciente de tecnologías de la imagen, desde las fotos violentas de Perfecto, pasando por la videograbadora en la cual don Roberto mira películas norteamericanas (notablemente Citizen Kane), hasta las cámaras de "vigilancia y seguridad" a través de las cuales don Roberto tiene su única relación con sus nietos, está en una relación de complicidad con el consumo y desgaste de los cuerpos, tanto del viejo como de los jóvenes que le proveen de sangre. Los tres empleados tienen que buscar cuerpos en las calles nocturnas porque Adolfo descubrió las fotografías comprometedoras de Perfecto: 
la imagen consume y evacua los cuerpos casi exactamente en la forma descrita por Henri Lefebvre en La Production de l'espace. ${ }^{9}$ Florencia lee cómics y fotonovelas de los cuales sus acciones parecen ser una mimesis: los medios masivos llevan inscrita en su lógica la ferocidad de las relaciones urbanas que ellos mismos ayudan a constituir y a mediar. El papel de la televisión en la película es el de fetichizar la violencia, convirtiendo el miedo en un mito urbano de monstruos y vampiros, y los cuerpos en espectáculos de terror. $\mathrm{Al}$ final de la película el mito parece ser auto-generador: se "descubre” por televisión al monstruo de los mangones, un negro (evidentemente) quien actúa con gusto el papel de monstruo-otro (hasta con dientes postizos de vampiro) prescrito en la misma lógica urbana y massmediática.

LAS CEREMONIAS DEL (AUTO-)CONSUMO.

La virgen de los sicarios fue realizada en 1999 por el cineasta suizo-colombiano Barbet Schroeder, basada en la novela homónima del autor colombiano Fernando Vallejo, quien escribió también el guión. Se trata de la “cultura” extrema de violencia que invadió a Medellín a finales de los años ochenta y durante los noventa, y es la más reciente de una serie de películas que tratan de las vidas “invisibles” de los jóvenes marginales y desocupados que están involucrados en la delincuencia y los asesinatos de revancha del sicariato. $\mathrm{La}$ virgen de los sicarios no es la mejor de las películas colombianas que tratan de este tema; ese título habría que otorgárselo a los extraordinarios estudios fílmicos del poeta y cineasta Víctor Gaviria, Rodrigo D. No futuro y La vendedora de rosas, los cuales he comentado en otras publicaciones (Kantaris). Escojo esta película por ser la más reciente y también la más explícitamente violenta; compararé, sin embargo, su puesta en escena de un encuentro entre cultura y violencia con la que encontramos en Rodrigo D.

Sería correcto afirmar que por un lado La virgen de los sicarios es un estudio sobre los efectos deshumanizadores de la violencia urbana. La película nos enfrenta a la banalidad de la violencia y a la desensibilización moral a través de un efecto de repetición acumulativa. Barbet Schroeder ha constatado que al entablar el proyecto de la película no estaba muy seguro de que la novela pudiera adaptarse a la pantalla por el alto número de muertes violentas -18 en total-que contiene. La película tiene menos, pero siguen siendo muchas, y muchas de ellas son asesinatos por capricho sin más motivo que un disgusto cualquiera. Así lo explica Schroeder:

Yo quería que la violencia se volviera... quería que los espectadores sintieran, como los personajes, una especie de anestesia progresiva hacia la violencia, como cualquier persona que quiere seguir viviendo en Medellín. (DVD Extra)

A continuación explica que en Medellín-que se tilda de Medallo o Metrallo(de metralleta) en la película- la tasa de impunidad por los crímenes violentos es de un 98\%. El argumento

\footnotetext{
9 “'Transportados fuera de sí, transferidos, los cuerpos vivientes se vacían a través de los ojos [...]. La entrada de informaciones, la llegada masiva de mensajes, se choca con este movimiento inverso: la evacuación en el seno mismo del cuerpo, de su vida, de su deseo” (118, traducción mía).
} 
trata de un escritor colombiano, cansado de la vida, cínico, con el mismo nombre del autor de la novela Fernando Vallejo, que regresa a Medellín después de muchos años viviendo en el exterior. Dice que ha regresado a Medellín para morir, pero allí se enamora de un joven sicario, Alexis, a quien conoce en un burdel gay, y empieza a caer, junto con nosotros, en el caos moral de la ciudad. La película emplea varias convenciones estereotipadas del cine narrativo para representar la violencia, pero en la segunda mitad, después de la muerte de Alexis, y con el desmoronamiento del mundo de Vallejo, empieza a usar un lenguaje visual marcadamente alucinatorio y experimental.

Uno de los chicos de la película proclama "Nacimos para morir”, y así nos obliga a reconocer la falta severa de dimensión temporal en la vida de estos jóvenes habitantes de la calle. Para un público colombiano, esta frase no puede entenderse sino como una cita del libro perturbador del antropólogo Alonso Salazar, No nacimos pa'semilla, que se ha convertido en texto clave de indagación y explicación de la cultura del sicariato. Así lo analiza Salazar:

El sicario ha incorporado el sentido efímero del tiempo propio de nuestra época. La vida es el instante. Ni el pasado ni el futuro existen. [...] El sicario lleva la sociedad de consumo al extremo: convierte la vida, la propia y la de las víctimas, en objetos de transacción económica, en objetos desechables. (200)

Este mismo tema se subraya fuertemente en la película, donde la profundidad temporal de Fernando, con su nostalgia por el Medellín de su infancia que ahora existe solamente en algunos lugares olvidados de la ciudad (algunos bares, el "Patio del Tango"), se contrasta permanentemente con la vida efímera en la que viven Alexis y sus compañeros de la calle.

A pesar de su representación directa de varios actos de violencia, incluso tiroteos y matanzas, la película logra desafiar el fetichismo de la violencia, principalmente al crear una incomodidad creciente en el espectador a medida que los cuerpos se acumulan, cada uno provocando menos simpatía que el anterior, y una respuesta cínica y escueta de parte de Fernando. Lo interesante aquí es que esta incomodidad creada en el espectador resulta ser una especie de “pánico moral” por la desensibilización que la misma película nos está causando. En este sentido emplea la desensibilización como una forma de desfetichización, vaciamiento de nuestras respuestas morales hacia la violencia. Así la violencia urbana es experimentada, como en otro momento lo fuera la naturaleza misma, como una vorágine que devora los sentidos, tanto las sensaciones como las significaciones. En este contexto, el recurso a la religión -el culto a la Virgen de los sicarios, las "balas rezadas” que ellos emplean para matarse entre sí- se da a entender como un culto fetiche que intenta compensar lo que se está perdiendo en el espacio de los flujos, pantalla que sustituye a la pérdida de lugar, de raigambre, y hasta de futuro. Para Fernando, a pesar de su ateísmo, las repetidas visitas a las iglesias, algunas convertidas en centros de tráfico de drogas, tal como su búsqueda de los recintos de su juventud (bares olvidados, sitios de tango frecuentados ya sólo por ancianos), se entienden como intento de rescatar la memoria, tanto personal como urbana, y como contrapeso a la vorágine espacial y temporal del consumo: "La identificación de la juventud con el presente tiene [...] dos escenarios claves: el de la destrucción de la memoria de nuestras ciudades, y el de la acelerada obsolescencia de los objetos cotidianos” (Martín-Barbero, Al sur... 241). 
Al mismo tiempo, nos damos cuenta de la creciente complicidad de Fernando con los procesos de consumo y sustitución de los cuerpos que comenta Salazar arriba. Desde el principio, su relación con los sicarios ha sido comercial, al comprar y consumir sus cuerpos, al regalarles los objetos de consumo que ellos codician para sí mismos o para sus familias (un Aiwa, una nevera Whirlpool). Como estos objetos, los chicos resultan ser sustituibles: mueren rápidamente y los reemplazan otros. Al morir Alexis, Fernando encuentra en la calle a un chico casi idéntico, por lo menos en su manera de vestirse, que se llama Wílmar, pero que igualmente podría llamarse Fáber, Eder, Tyson Alexander, Jason, Wílfer, como dice Fernando. Esta complicidad con el tiempo del objeto de consumo se vincula en la película con un sistema de representaciones que va desde la "ciudad letrada" hasta la "ciudad virtual" o massmediática. Hablando del desprecio de la élite cultural hacia las formas y contenidos de la cultura popular y la de masas, Martín-Barbero señala que:

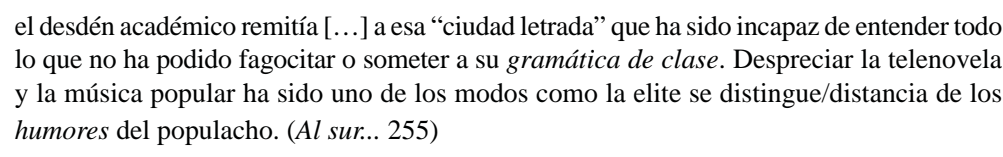

En la película, Fernando se señala como “el último gramático de Colombia”, y muestra abiertamente su desprecio hacia los punkeros, la música popular en los taxis, el metal y rock duro que escuchan los jóvenes sicarios, y la forma de hablar de la gente. Es más, esta "gramática de clase" se muestra cómplice del asesinato, porque al expresar su desprecio, casi siempre el sicario-amante de turno saca su pistola y despacha al responsable del "agravio": a un punkero que no dejaba dormir a Fernando por estar tocando tambor en el apartamento vecino, a un taxista que lo amenazó con un machete porque Fernando le había ordenado que apagara la música del carro.

Una secuencia muestra claramente la imbricación de la gramática y la violencia, es decir, la violencia de un sistema de representaciones excluyentes que proviene, históricamente, de la ciudad letrada, pero que veremos sustituirse en la película por la ciudad virtual. Alexis y Fernando están viajando en un vagón del metro de Medellín (de construcción reciente en la época), que está lleno de gente de clase popular. Éste nota que hay un niño con los zapatos sucios parado en una silla nueva (la cámara lo muestra con un plano desde su punto de vista). Fernando, que durante toda la película demuestra una misoginia feroz sobre todo hacia mujeres embarazadas o con niños pequeños, le dice a la madre del niño que lo baje y la regaña por no respetar la limpieza del metro. Inmediatamente, dos señores la defienden:

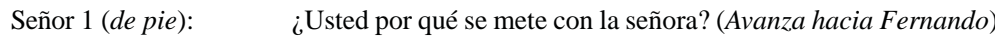
Esta gonorrea piró...

Fernando (miedoso): $\quad$ Este otro loquito. ¿Cuál piró? ¿Es que te creés muy bonito? Señor 2 (sentado): Callate ya gonorrea, ya te dijeron, piró.

Fernando:

Quériqueza de lenguaje la de estos caballeros. No salen de gonorrea y piró. Si supieran con quién están tratando. (Se levanta el Señor 2) Con el último gramático de Colombia. Con el que descubrió el proverbo. ¿Que saben qué es? Es la palabra que está en lugar del 
verbo. (Plano corto del Señor 1, pensando cómo reaccionar) Un ejemplo: dijo que lo iba a matar y lo hizo. (Primerísimo plano de la mano de Alexis sacando su pistola del cinturón) Este "hizo" que está en lugar de “matar” es el proverbo.

En este momento, el Señor 1 se inclina hacia Fernando y lo empuja con la mano, pero Alexis, que está a su lado, mete la pistola en el pecho del Señor 1, dispara, rápidamente apunta al Señor 2 y lo mata a él también. Las palabras de Fernando aquí, como en muchas secuencias de la película, actúan claramente como "proverbos", es decir como generadores de actos de violencia. En esta secuencia, la película nos hace conscientes de esta relación directa entre una gramática de clase amenazada por los lenguajes populares, por la presencia del otro "sucio" e "inculto" en la ciudad letrada, y la violencia generada desde ella que va destruyendo este mismo concepto de ciudad como escenario de privilegios.

Pero la ciudad letrada es ya claramente anacrónica en esta película, habiendo sido sustituida por las “urbanías” massmediáticas que desanclan el acoplamiento excluyente de ciudad-ciudadanía (Martín-Barbero 2005). Propongo que las paradojas representacionales expresadas en esta película, tal como en Pura sangre, son inherentes a la representación televisual de la violencia (e incluyo el cine dentro del régimen de lo "tele-visual” desde una perspectiva filosófica). Como lo señala Lefebvre, vivimos en una edad de capitalismo de la imagen y de los medios, dentro de un régimen espacial vigilado, donde el poder o la falta de poder de una persona se determina por su visibilidad o invisibilidad en el régimen visual de los medios y los procesos figurativos del capitalismo (116-18). Expresando esta idea de forma más sencilla, Fernando comenta en la película que "el que no sale en televisión no existe”. De hecho, el cine no puede representar inocente y objetivamente el proceso violento de la segmentación y fragmentación del espacio cuando el cine mismo está constituido en, y es constitutivo de, la geometría del poder de los regímenes visuales de la modernidad y la posmodernidad.

Bastará un último ejemplo tomado de La virgen de los sicarios: una secuencia bastante alegórica donde vemos a Alexis mirando televisión cuando llega Fernando de la calle. En ese preciso momento el (ex) presidente de Colombia, César Gaviria, está pronunciando un discurso televisado sobre la privatización de las empresas públicas, iniciativa que, él dice, "beneficiará a todos los colombianos". Es la retórica global del neoliberalismo que ha fracasado de modo tan espectacular en muchos países de la región. Fernando le dice a Alexis que apague el televisor, pero éste se pone de pie, va a su pieza, y vuelve con una pistola en la mano. Apunta con el arma a Fernando, quien retrocede de miedo, pero súbitamente da vuelta hacia el televisor y dispara sobre la imagen de Gaviria. El televisor explota y, entre carcajadas de ambos, Alexis lo levanta y lo tira por la ventana del apartamento que se encuentra en el tercer piso.

Esta secuencia vuelve literal, de manera dramática, la relación entre los regímenes televisivos del capitalismo massmediático, la pérdida de profundidad temporal en la cultura del consumismo, y la reducción de los cuerpos humanos a unos objetos de consumo desechables, lo que Martín-Barbero señala como la "estrecha simetría entre la expansión/estallido de la ciudad y el crecimiento/densificación de los medios y redes electrónicas” (Al sur... 132). Creo muy significativo el hecho de que el asesinato de una pantalla aquí inaugura toda una 
serie de asesinatos cada vez más arbitrarios que ejecutará Alexis en su afán por complacer a Fernando. Al vincular directamente las políticas globales de privatización de los bienes comunes, el fetichismo de los objetos de consumo, y la mediatización, a la compra y venta de la vida en las calles de Medellín, esta película -o por lo menos su guión y el libro en que se basa- está elaborando una crítica de la producción sistémica de la violencia y la complicidad de los regímenes audiovisuales con ella.

LA FIESTA DE LA PLATA EN LA ERA DEL VACío

Hay una diferencia clave entre la óptica de Vallejo-Schroeder en La virgen de los sicarios, y la de Víctor Gaviria en su trilogía sobre Medellín. La secuencia del metro descrita arriba sería imposible de imaginar en una película como Rodrigo $D$. No futuro porque el método de Gaviria en esta película elabora precisamente la densidad cultural de los lenguajes y hablas populares, y la película se convierte en el lugar imaginario de su enunciación. ${ }^{10}$ En La virgen, la violencia es la de un sistema letrado, generada desde el "proverbo", decidida al exterminio de la "estridencia” del habla popular, de la música popular (sea el vallenato, el rock o el punk, que además no se distinguen para Fernando), mientras que en Rodrigo $D$. la violencia es una acumulación de signos estancados, que tienen su expresión simbólica en los gritos enloquecidos y las disonancias de las propias canciones punk de estos chicos (que además se usan como banda sonora de la película). En La virgen, los sicarios no tienen cultura si no es la del (auto-)consumo y el culto a la Virgen, y su lenguaje (cuando hablan) es una deformación y degradación del español (no obstante la ironía con que Fernando señala esta degradación); en Rodrigo D., al igual que La vendedora de rosas, los jóvenes tienen un exceso de cultura simbólica-ritos complejos, historias para contar-y un lenguaje barroco de hibridaciones insólitas y metáforas poéticas:

Ese lenguaje -que está relacionado tan fuertemente a la identidad de estos niños- tiene algo de monstruoso; esa, creo, es la violencia lingüística que sienten algunos espectadores. Yo no puedo, sin traicionarme, hacer de corrector del habla, y de gramático y preceptor del buen decir de los actores naturales. Ese lenguaje es mucho más importante que la película misma porque allí está la historia (la de la ciudad, la de los muchachos, la de los muertos, la de la injusticia, la de las experiencias de vida, la de la solidaridad y la identidad). (Gaviria, en Jáuregui, “Violencia”, 99)

\footnotetext{
${ }^{10}$ Disto completamente del análisis de Antonio Gómez, quien arguye que Gaviria filma y “traduce” a los jóvenes sicarios desde afuera mientras que Vallejo escribe desde el interior de esta violencia, adoptando su nihilismo. Me parece exactamente al revés: Fernando es el que explica y traduce constantemente el lenguaje de los sicarios para un público de afuera (y además casi no deja hablar a los jóvenes en su afán por enseñarles, de modo bastante didáctico, su visión nihilista), mientras que la película de Gaviria se niega a la traducción ni del lenguaje ni de los códigos simbólicos de estos jóvenes, insistiendo (para desconcierto de algunos espectadores) en la complejidad cultural de su sistema de signos. Para una lectura mucho más compleja de las diferencias entre estas obras, véase Jáuregui y Suárez.
} 
Sumas y restas (2004) ${ }^{11}$ es la película más reciente de este ciclo sobre Medellín, y se trata de las historias de los “traquetos” de la década de los ochenta. “Traqueto” es una palabra colombiana que en la definición de Juana Suárez “denomina a quienes, ilusionados por el dinero fácil, lograron amasar un capital considerable por medio de trabajos intermedios como la preparación, la producción y la distribución de droga para los grandes capos” (34), y que, según el folleto de publicidad de la película, "proviene del ruido que producen las ametralladoras al disparar”. Al alejarse ya un poco de la exclusión social y al querer “poner relato" 12 al fenómeno confuso del narcotráfico y del traqueteo de los ochenta -que hundió a Medellín y al país entero en los simulacros feroces y violentos de la plata- la película se acerca a una temática y a un modo de enunciación más bien alegóricos, por ser este tema un punto clave en las desarticulaciones del ya debilitado contrato social a nivel nacional y más allá. Los actores naturales en esta película ya no señalan un mundo de densidades culturales intraducibles (lugar donde "surgen memorias olvidadas inalcanzables mediante los procedimientos tradicionales de investigación”, Gaviria en Jáuregui, 93), y eso por una razón bastante sencilla: su lógica es la del mercado llevada a la euforia, una "utopía" de desregulación e impunidad de la cual estarían orgullosos los economistas del Fondo Monetario Internacional. Es una lógica que se difundió por muchas de las estructuras sociales y políticas de la nación y que se vinculaba tanto con la globalización “negativa” (el crimen globalizado, la desestabilización de las economías nacionales, el alza en el endeudamiento muchas veces por corrupción) como con el clima oficial de neoliberalismo internacional (la "apertura” económica, la privatización, la sustitución del Estado por el mercado) que vimos arriba. Es verdad que la fuerte lealtad, casi simbólica, entre los traquetos y sus empleados y sicarios es un descubrimiento original de esta película, junto con la forma en que éstos se van transformando de empleados en "soldados” (Ruffinelli 38), llenando el vacío del Estado. Es muy significativo que no aparece ni un agente del Estado en Sumas y restas (sólo aparecen sus simulacros), y que aun con el secuestro de Santiago, miembro de la clase empresarial, a sus amigos y a su familia no se les ocurre en ningún momento recurrir a la policía.

La película cuenta la historia de Santiago Restrepo, ingeniero de construcción, casado con hijo recién nacido, de familia adinerada, viejos empresarios de Medellín, quien se va metiendo poco a poco en el mundo del traqueteo. Atraído por la libertad de su amigo de infancia, el Duende, que se ha enriquecido con el narcotráfico, Santiago empieza a aceptar contratos de diseño y construcción de Gerardo, amigo traqueto del Duende, y dueño de una “cocina” de cocaína. Santiago descubre que el padre de Gerardo era trabajador en el negocio de transportes de su propio padre. Gerardo se ha enriquecido con el traqueteo, y es todo un "papá” para sus trabajadores y amigos, a quienes recompensa con flujos aparentemente ilimitados de dólares, regalos lujosos, fiestas locas, y mucha droga (la actuación espléndida de Fabio Restrepo en el papel de Gerardo, hablador incansable, capaz de amar y de matar

\footnotetext{
${ }^{11}$ Este análisis se basa en el estreno de Sumas y restas, en presencia del director, durante el Simposio Internacional de Cultura Visual en América Latina, “The Conundra of Vision”, 18 a 19 de marzo 2005, Universidad de Cambridge, Inglaterra.

${ }^{12}$ Sesión de preguntas y respuestas después del estreno de Cambridge, y conversaciones con Víctor Gaviria durante el simposio.
} 
con una palabra, o a veces una mirada, es un verdadero acierto de esta película). Santi empieza a codiciar la plata y la droga y pasa más y más tiempo con el grupo de Gerardo, abandonando lentamente a su esposa y a su hijo. Pero comete un error fundamental al no asistir a los funerales del hermano de Gerardo, Alberto, y a partir de ahí empieza a desarmarse implacablemente la vida de Santiago, hasta dejarlo en la ruina.

Hay una relación casi dialéctica entre Sumas y restas y las películas de Gaviria que tratan de la exclusión social -“dialéctica de la acumulación/marginalidad” (Giraldo y López 284) - y creo necesario ver estas películas en conjunto para poder entender la envergadura del proyecto que representan. A pesar de ser la última de las tres películas, cronológicamente Sumas y restas representa el principio del desarraigo, el proceso de encantamiento por la euforia de los flujos acompañado del desencaje y desmantelamiento de las estructuras más básicas de la sociedad, y no puede entenderse completamente sino como contrapartida del mundo fragmentado de astillas dispersas que recogen Rodrigo D. y La vendedora:

El marginado que habita en los grandes centros urbanos en Colombia, y que en algunas ciudades ha asumido la figura del sicario, no sólo es la expresión del atraso, la pobreza, el desempleo, la ausencia de la acción del Estado [...]. También es reflejo, acaso de manera más protuberante, del hedonismo, el consumo, la cultura de la imagen, la drogadicción, en una palabra, de la colonización del mundo de la vida por la modernidad. (Giraldo y López 261)

Si “la violencia en Colombia ha sido una potencia económica” (273), el narcotráfico es el catalizador que lleva esta potencia hasta su más “pura” expresión-la violencia como lógica íntima del consumo-, y la pone en circulación desde las calles de Medellín hasta las calles de Miami. Y la circulación resulta ser una de las metáforas más fuertes de la película, desde la vorágine de su primera imagen -plano cenital de una caneca redonda llena de pre-productos líquidos de la cocaína, en mezcla continua y vigorosa hasta formar casi un torbellino-, hasta las vueltas locas de los carros conducidos a alta velocidad por las carreteras de Medellín bajo los efectos de la cocaína y el alcohol. Estas vueltas parecen traducir una circulación más profunda y total, una que hace desaparecer hasta la huella de lo real. Se resume esta idea en la descripción que nos da el contable de Gerardo del proceso de lavado de dinero a través de los bancos, descripción animada acompañada con muchos movimientos circulares de la mano:

Ay hermano, vea, [la gerente del banco] me dijo, “consígame dos cédulas”, y las trajimos de allá de dos vaqueros de Ayapé. Entonces, ella me abre dos cuentas, y empieza a moverme el dinero de cuenta a cuenta hasta que se pierda la huella. Una putería hermano, una putería, una putería. Estamos tranquilos por ese lado.

Pero quizás la metáfora más representativa de la película es la disolvencia, tanto en el sentido literal de disolución como en el sentido cinematográfico del fundido (entre tomas y a veces fundido a negro), técnica que se emplea muy a menudo en Sumas y restas. Una secuencia, o más bien una imagen, de la película resulta casi iconográfica en este sentido, e inaugura toda una serie de “disolvencias” sociales y económicas. Casi al principio de la película vemos al Duende y dos socios sentados en la mesa de un restaurante español, hablando animadamente de plata y mercancía (“un Rolex a mitad de precio”), cuando 
el Duende le dice a los socios que mejor hablen de "negocios". Les explica que tiene trescientos “cositos” para que le consigan clientes, y que tiene la muestra. Los lleva a su "oficina”, un cuarto de limpieza del restaurante, donde llena un vaso de vidrio con un líquido transparente, saca la bolsita de cocaína, y empieza a disolver el polvo blanco en el líquido, mientras que todos hacen comentarios alucinados: "véalo que sube, véalo que sube a nada”. La cámara muestra en primerísimo plano los glóbulos blancos que bajan hasta el fondo del vaso, vuelven a subir, y se disuelven en nubes blancas. La imagen se funde lentamente con un travelling a lo largo de la parte inferior de un camión en un garaje, que, nos damos cuenta después, es el centro de operaciones de Gerardo instalado en un lote vacío de la ciudad. Estamos plenamente en el espacio de los flujos -flujos de dinero, flujos de sustancias, transportes, lotes, construcción, comunicaciones- espacio donde, en la frase famosa de Marx, "todo lo sólido se desvanece en el aire".

A la "pureza” y blancura de estas solvencias y disolvencias, a la embriaguez de su levedad, se contrapone el descenso lento hacia la violencia real que sostiene estos simulacros y alucinaciones. La violencia en esta película -en la segunda mitad-es más cruda que en las otras películas de Gaviria, pero corresponde a un fenómeno desgarradoramente violento. No se fetichiza en ningún momento: se revela más bien como una maquinaria implacable que va desarmando relaciones entre socios, amistades y familia. Desde el fondo de su pequeño calabozo de rejas (filmado desde adentro con panorámicas lentas de ángulo extremadamente confinado y acercamientos extremos), enterrados vivos, a los secuestrados Santiago y el viejo don Roberto les está revelada la dimensión carcelaria de estos flujos eufóricos, estancados ya en las secreciones mismas de sus cuerpos: "esto que huele a sangre, a muerto, a mierda [...] ¿Qué he hecho? [...] Esto... no tiene por que pasarle... a nadie”, murmura don Roberto mientras que Santiago se hunde en un silencio total y aterrador.

CONCLUSIÓN

En Sumas y restas, la cocaína "es lo más parecido a plata que hay ahora”, en palabras de un cliente de Santiago que quiere pagarle una propiedad de finca raíz con "mercancía” en vez de dinero. La cocaína, como el dinero en los análisis de Marx, es una fuerza "revolucionaria", capaz de descolocar, violentamente, todas las estructuras de la sociedad, disolviéndolas en una cadena infinita de sustituciones sangrientas. Ésta puede ser, quizás, la metáfora más “pura” de la violencia que enuncian las películas examinadas aquí: el dinero, como la cocaína, es una acumulación de violencias y de vaciamientos, la expresión reificada de su potencia disolvente. Desde las transfusiones de fluidos que vimos en Pura sangre -alegoría de la disolución de los cuerpos en el consumo compulsivo de la ciudad-, pasando por el asesinato a una pantalla televisiva en La virgen de los sicarios -momento clave que inaugura toda una cadena de cadáveres desechables y sustituibles-, llegamos en Sumas y restas a la imbricación de la violencia con el sistema de representación más abstracto pero más poderoso de la sociedad, transformado en metáfora de la disolución total. La violencia no se puede representar sin desplazamientos porque es, de por sí, una dislocación, la expresión misma de un sistema de representaciones que excede y deshace todo marco de referencia. Las películas de la tercera violencia colombiana son la búsqueda 
de una serie de metáforas a través de las cuales se pueda imaginar, y quizás empezar a nombrar, las tramas y los traumas individuales y colectivos de la Violencia.

\section{BiBLIOGRAFÍA}

Castells, Manuel. End of Millennium. The Information Age: Economy, Society and Culture. III. Malden: Blackwell, 1998.

The Rise of the Network Society. The Information Age: Economy, Society and Culture. I. Malden: Blackwell, 1996.

Giraldo, Fabio y Héctor Fernando LópezA. “La metamorfosis de la modernidad”. Colombia: el despertar de la modernidad. Fernando Viviescas y Fabio Giraldo Isaza, eds. Bogotá: Foro Nacional por Colombia, 1991. 248-310.

Gómez, Antonio. “Traducciones de Medellín: Rodrigo D. No futuro y La virgen de los sicarios”. Número monográfico: Imagen y subalternidad: el cine de Víctor Gaviria. Revista Objeto Visual 9 (Caracas, julio 2003): 82-90.

Harvey, David. The Urban Experience. Oxford: Blackwell, 1989.

Jáuregui, Carlos. "Violencia, representación y voluntad realista: entrevista a Víctor Gaviria”. Número monográfico: Imagen y subalternidad: el cine de Víctor Gaviria. Revista Objeto Visual 11/9 (Caracas, julio 2003): 91-104.

y Juana Suárez. "Profilaxis, traducción y ética: la humanidad desechable en Rodrigo D. No futuro, La vendedora de rosas y La virgen de los sicarios”. Número monográfico: Literatura y cine en América Latina. Revista Iberoamericana LXVIII/199 (Pittsburgh, abril-junio 2002): 367-92.

Kantaris, Geoffrey. “Allegorical Cities: Bodies and Visions in Colombian Urban Cinema”. Estudios interdisciplinarios de América Latina yel Caribe 9/2 (Tel Aviv, julio-diciembre 1998): 55-73. <http://www.tau.ac.il/eial/IX_2/kantaris.html>.

"Periferias de la globalización: la disfasia temporal en La vendedora de rosas de Víctor Gaviria”. Número monográfico: Imagen y subalternidad: el cine de Víctor Gaviria. Revista Objeto Visual 11/9 (Caracas, julio 2003): 70-81.

Lefebvre, Henri. La Production de l'espace. París: Anthropos, 1974.

Martín-Barbero, Jesús. Al sur de la modernidad: comunicación, globalización y multiculturalidad. Pittsburgh: Instituto Internacional de Literatura Iberoamericana, 2001.

Oficio de cartógrafo: travesías latinoamericanas de la comunicación en la cultura. Bogotá y México: FCE, 2002.

“Urbanías y ciudadanías: hibridizaciones culturales en la ciudad”. Ponencia en el marco del Simposio Internacional de Cultura Visual en América Latina, "The Conundra of Vision”, Cambridge, UK, 18 a 19 de marzo 2005.

Massey, Doreen. Space, Place and Gender. Cambridge: Polity Press, 1994.

Medina, Álvaro, ed. Arte y violencia en Colombia desde 1948. Bogotá: Museo de Arte Moderno/Norma, 1999.

"El arte y la violencia colombiana en la segunda mitad del siglo XX". Arte y violencia en Colombia desde 1948. Álvaro Medina, ed. Bogotá: Museo de Arte Moderno/Norma, 1999. 10-119. 
Metz, Christian. Psychoanalysis and Cinema: The Imaginary Signifier. Celia Britton, trad. Londres: Macmillan, 1982.

Ortiz, Renato. Otro territorio: ensayos sobre el mundo contemporáneo [1996]. Ada Solari, trad. $2^{a}$ ed. Bogotá: Convenio Andrés Bello, 1998.

Pisingaña. Dir. Leopoldo Pinzón. Colombia, 1984. 35mm/Color.

Pulecio, Enrique. “Cine y violencia en Colombia”. Arte y violencia en Colombia desde 1948. Álvaro Medina, ed. Bogotá: Museo de Arte Moderno/Norma, 1999. 152-83.

Pura sangre. Dir. Luis Ospina. Colombia, 1982. 35mm/Color. 98mins.

Rodrigo D. No futuro. Dir. Víctor Gaviria. Colombia, 1988. 35mm/Color. 90 min.

Ruffinelli, Jorge. Víctor Gaviria: los márgenes, al centro. Madrid: Turner, 2005.

Salazar, Alonso J. No nacimos pa’ semilla [1993]. Bogotá: Centro de Investigación y Educación Popular, 1997.

Soplo de vida. Dir. Luis Ospina. Colombia, 1999. 35mm/Color. 107mins.

Suárez, Juana. "Los estragos de la euforia: dinámicas urbanas en Rodrigo D. No futuro, La vendedora de rosas y Sumas y restas”. Número monográfico: Imagen y subalternidad: el cine de Víctor Gaviria. Revista Objeto Visual 11/9 (Caracas, julio 2003): 33-53.

Sumas y restas. Dir. Víctor Gaviria. Colombia, 2004. 35mm/Color. 108mins.

La vendedora de rosas. Dir. Víctor Gaviria. Colombia, 1998. 35mm/Color. 110mins.

La virgen de los sicarios. Dir. Barbet Schroeder. Colombia-España-Francia, 1999. Digital/ Color. 98min. 